Saint Louis University School of Law

Scholarship Commons

All Faculty Scholarship

2012

Shifting Public Health Priorities and the Global Effort to Prevent a

Bird Flu Pandemic

Robert Gatter

Follow this and additional works at: https://scholarship.law.slu.edu/faculty

Part of the Health Law and Policy Commons, and the International Law Commons 


\section{S A I N T L O U IS}

U N N I V V E

\section{SCHOOL OF LAW}

\section{SAINT LOUIS UNIVERSITY SCHOOL OF LAW Legal Studies Research Paper Series}

No. $2012-15$

Shifting Public Health Priorities and the Global Effort to Prevent a Bird Flu Pandemic

Robert Gatter

Working Paper 


\title{
Shifting Public Health Priorities and the Global Effort to Prevent a Bird Flu Pandemic
}

\author{
Robert Gatter $^{1}$
}

\section{Introduction}

Global strategy to control highly pathogenic avian influenza (HPAI) has changed dramatically since 2003 when it was first reported that a confirmed bird flu jumped the species barrier to infect a human in Hong Kong. ${ }^{2}$ What started as a three-year project to control and eradicate HPAI is already entering its eighth year, and the United Nation's Food and Agriculture Organization (FAO) announced in 2011 that the goal of eliminating HPAI from countries where it is now endemic cannot be achieved for at least another ten years. ${ }^{3}$ What started as a standalone project targeting HPAI has been folded into a much larger initiative - "One World, One Health" ${ }^{-}$to overhaul animal and human disease surveillance and data-sharing infrastructure so

\footnotetext{
${ }^{1}$ Professor of Law and Co-Director of the Center for Health Law Studies, Saint Louis University School of Law. Funding in support of the research for and writing of this Article was provided in the form of a summer research grant by Saint Louis University School of Law.

${ }^{2}$ See J. Otte et al., Evidence-Based Policy for Controlling HPAI in Poultry: Bio-Security Revisited, Research Report, Pro-Poor Livestock Policy Initiative at 2 (December 2006) available at http://www.fao.org/ag/againfo/programmes/en/pplpi/docarc/rep-hpai biosecurity.pdf ("Outbreaks of . .. [HPAI] were first reported in Southeast Asia in late 2003, although the current emergence of H5N1 is now considered to have occurred as early as 1996 ....").

${ }^{3}$ FAO, Approaches to Controlling, Preventing and Eliminaring H5N1 Highly Pathogenic Avian Influenza in Endemic Countries at x (2011).

${ }^{4}$ For background on the "One World, One Health" initiative, see http://www.onehealthinitiative.com (last visited September 25, 2011).
} 
as to better track and respond to a host of diseases residing at the animal-human interface. ${ }^{5}$ And what started as program to prevent HPAI infections of poultry and humans by focusing primarily on backyard farmers in developing countries has shifted to a program primarily concerned with preparing for a potential pandemic and focusing prevention efforts on commercial poultry producers. As a result, prevention is taking a backseat to response strategies, and, within prevention efforts, the welfare of thousands of backyard poultry farmers is taking a backseat to biosecurity in commercial poultry sectors.

Evidence of this shift in priorities in the global fight against HPAI can be found most clearly in program funding trends. In late 2008 and into 2009, financial commitments from international donors for all HPAI programs dropped significantly. ${ }^{6}$ Meanwhile, within HPAI programs, funding shifted substantially away from animal biosecurity projects and into human response and preparedness work. ${ }^{7}$

This Article examines the reasons for this shift in priorities. It highlights three reasons in particular: the global experience with the H1N1 pandemic, the rise of the "One Health" movement, and hard-learned lessons about both the locus of HPAI risk within the various sectors of poultry production in developing nations and the difficulty of changing behaviors in the name of making poultry production more secure. The Article concludes that the twin strategies of (1) building a public health infrastructure that can better respond to HPAI infections and (2) boosting preparedness for a potential human pandemic, while well-intentioned, are siphoning

\footnotetext{
${ }^{5}$ See FAO, Third Report (Oct. 2008 - Dec. 2009) of the Global Programme for the Prevention and Control of Highly Pathogenic Avian Influenza at 90-99 (2010); UN and World Bank, Animal and Pandemic Influenza: A Framework for Sustaining Momentum at 81-119 (July 2010).

${ }^{6}$ See FAO, Fourth Report (Jan - Dec 2010) of the Global Programme for the Prevention and Control of Highly Pathogenic Avian Influenza at 19 (2011).

${ }^{7}$ See UN and World Bank, Animal and Pandemic Influenza: A Framework for Sustaining Momentum at 38, figure 2-5 (July 2010).
} 
resources away from HPAI prevention at least in the short-run. Likewise, the strategy within HPAI prevention of concentrating efforts to improve biosecurity in commercial poultry production sectors leaves the vulnerable population in the backyard sector at greater risk for poultry infections that threaten their livelihoods and human infections that threaten their lives unless and until the benefits of commercial biosecurity trickle down to the backyard sector. In the end, we cannot afford public health strategies that short-shrift HPAI programs generally or HPAI prevention efforts in particular - including prevention efforts in the backyard farming sector - while focusing on other priorities.

\section{A. The Pandemic Risk of HPAI and Strategies for Managing that Risk}

HPAI poses a risk to human health worldwide primarily because it is a very likely source of a novel influenza. Novel influenza strains that infect and are readily communicable among humans pose a pandemic risk because humans have not had an opportunity to build a natural immunity to such strains. ${ }^{8}$ Consequently, a new strain has the potential to ravage defenseless human populations quickly. Indeed, it was novel strains that killed as many as 100 million people worldwide in 1918-1919, one million worldwide in 1957-1958, and 40,000 in the U.S. alone in 1967-1968. ${ }^{9}$

\footnotetext{
${ }^{8}$ See U.S. Department of Health and Human Services, About Pandemics, available at http://www.flu.gov/pandemic/about/index.html; John M. Barry, THE GreAt InfluenzA: THE STORY OF THE Deadliest Pandemic In History 107-115 (2005); N. Peiter M. O’Leary, Cock-A-Doodle-Doo: Pandemic Avian Influenza and the Legal Preparation and Consequences of an H5N1 Influenza Outbreak, 16 Health Matrix 511, 516 (2006).

${ }^{9}$ See CIDRAP, Pandemic Flu Overview: Pandemics of the $20^{\text {th }}$ Century, available at http://www.cidrap.umn.edu/cidrap/content/influenza/panflu/biofacts/panflu 20th.html; Laurie Garrett, The Next Pandemic? _ Foreign Affairs _ (July/Aug. 2005). For an exhaustive history of the most deadly human influenza pandemic of the $20^{\text {th }}$ Century, see generally John M. Barry, supra note 8.
} 
Influenza viruses mutate rapidly and resort their genetic make-up easily. ${ }^{10}$ As a result, novel influenza strains have a greater chance of emerging as compared to other infectious diseases the cellular and genetic make-up of which remain more stable over time. ${ }^{11}$

While novel influenza strains can emerge as a result of mutations of strains already circulating among humans, a novel strain with pandemic potential among humans is more likely to develop from an animal influenza that combines in new ways with other animal and human strains. $^{12}$ This is because animal strains are already significantly different from human strains, which increases the likelihood that humans lack any pre-existing immunity to those strains. The species barrier often prevents animal influenza strains from leaping to humans, but that barrier can be breached where there are opportunities for animal and human strains to combine into a novel strain that incorporates elements of the human strain so as to permit human infection. ${ }^{13}$

HPAI is of particular concern precisely because it arises from an environment where domestic and wild birds, domestic swine and humans interact routinely, giving ample opportunity for novel strains to develop that are capable of crossing the species barrier to infect humans. ${ }^{14}$ Avian influenza originated in wild aquatic birds that migrate (e.g., ducks and geese) and was passed to domesticated birds, including chickens, as wild birds visit and share space with those domesticated birds. ${ }^{15}$ There are further opportunities for inter-species mutations of

\footnotetext{
${ }^{10}$ See Barry, supra note 8; Garrett, supra note 9, at 6.

${ }^{11}$ See id.

${ }^{12}$ See Mark S. Klempner \& Daniel S Sharpiro, Crossing the Species Barrier - One Small Step to Man, One Giant Leap to Mankind, 350 N. Engl. J. Med. 1171 (2004).

${ }^{13}$ See id. See also Garrett, supra note 9.

${ }^{14}$ See Garrett, supra note 9; Thijs Kuiken et al., Host Species Barriers to Influenza Virus Infections, 312 Science 394 (2006).

${ }^{15}$ See Jessica H. Leibler et al., Industrial Food Animal Production and Global Health Risks: Exploring the Ecosystems and Economics of Avian Influenza, EcoHealth 2, online publication (May 13, 2009); William Choong,
} 
influenza where small-scale farmers combine fish and duck farming over warm-water ponds, ${ }^{16}$ and where domestic poultry come in close contact with swine on the same farm. ${ }^{17}$ Humans caring for domesticated birds, as well as perhaps fish and swine, come in close contact with those animals, creating routine opportunities for avian influenza strains to combine with human strains so as to start the process by which mutations could result in a strain that can leap the species barrier to infect humans. ${ }^{18}$ Moreover, such close contact between human farmers and their domesticated animals also permits infection with a novel avian influenza strain.

The initial global strategy to combat HPAI was based on a common story that a worrisome source of HPAI was backyard farmers from villages in several developing nations in southeast Asia and Africa. ${ }^{19}$ Public health officials recognize four categories of poultry producers in these nations: large commercial producers (sector 1), moderately sized commercial producers (sector 2), small-scale commercial producers (sector 3), and backyard or residential producers (sector 4). ${ }^{20}$ There was some evidence that commercial producers, especially in sectors 1 and 2, already employed biosecurity measures that diminished the risk of HPAI

Migratory Birds to Blame? Infected Birds on Long Flights May Have Spread the Virus, The Straits Times (Singapore) A4 (Jan 28, 2004); Garrett, supra note 9 at 5.

${ }^{16}$ See C.J. Feare, Fish Farming and the Risk of Spread of Avian Influenza, Bird Life International Research Paper at 5-7 (Mar. 2006) available at http://www.birdlife.org/action/science/species/avian_flu/index.html.

${ }^{17}$ See J.S.M. Peiris et al., Cocirculation of Avian H9N2 and Contemporary "Human" H3N2 Influenza A Viruses in Pigs in Southeastern China: Potential for Genetic Reassortment? 75 J. of Virology 9679 (2001).

${ }^{18}$ See id.

${ }^{19}$ See e.g., Paritosh K. Biswas et al., Risk for Infection with Highly Pathogenic Avian Influenza Virus (H5N1) in Backyard Chickens, Bangladesh, 15 Emerging Infectious Diseases (Dec. 2009) available at http://wwwnc.cdc.gov/eid/article/15/12/09-0643.htm. See also FAO et al, Contributing to One World, One Health: A Strategic Framework for Reducing Risks of Infectious Diseases at the Animal-Human-Ecosystems Interface 17 (October 2008), available at http://un-influenza.org/node/2341/.

${ }^{20}$ See UN and World Bank, supra note 5 at 122; FAO, The Global Strategy for Prevention and Control of H5N1 Highly Pathogenic Avian Influenza 11 n.2 (March 2007); John M. Omiti \& Sam O. Okuthe, An Overview of the Poultry Sector and Status of Highly Pathogenic Avian Influenza (HPAI) in Kenya - Background Paper 12-17 (undated) available at http://www.ifpri.org/sites/default/files/publications/hpairr04_kenya.pdf. 
infections. At the same time, there was clear evidence that backyard farmers engaged in husbandry practices that increased the risk of HPAI infections. ${ }^{21}$ These included the fact that domestic poultry were kept in communal flocks where different varieties of poultry were mixed and often come into contact with domestic animals of other species. ${ }^{22}$ Additionally, backyard farmers have neither the facilities nor the means to build facilities to isolate sick poultry from others in the flock or otherwise invest in biosecurity measures. ${ }^{23}$ Similarly, wild birds that visit these villages as they migrate mix with the domestic poultry that wander freely in common village areas. ${ }^{24}$ Finally, backyard farmers and their families live in close contact with poultry. ${ }^{25}$ All of this increases the likelihood that HPAI is introduced and transmitted among backyard poultry and between poultry and humans. It also increases the chances for viral re-assortment as an HPAI virus moves among various species.

Given this initial story of HPAI risk, global efforts targeted backyard farming practices. ${ }^{26}$ This perception was fed also by data showing that HPAI infection among humans was

\footnotetext{
${ }^{21}$ See Paritosh K. Biswas et al., supra note 19.

${ }^{22}$ See Paritosh K. Biswas et al., supra note 19; John M. Omiti \& Sam O. Okuthe, supra note 20 at 47-48.

${ }^{23}$ See Anni McLeod, Economics of Avian Influenza Management and Control in a World with Competing Agendas, 54(S1) Avian Diseases 374, 376 (2010).

${ }^{24}$ See John M. Omiti \& Sam O. Okuthe, supra note 20 at 47-48.

${ }^{25}$ See Paritosh K. Biswas et al., supra note 19; John M. Omiti \& Sam O. Okuthe, supra note 20 at 47.

${ }^{26}$ See World Bank, Implementation Completion and Results Report on Grant in the Amount of US\$15 Million to the Republic of Indonesia for the Avian Influenza Surveillance and Control Project (Oct. 29, 2011) (targeting smallscale and backyard poultry farmers) available at http://wwwwds. worldbank.org/external $/$ default $/$ main?pagePK=64193027\&piPK=64187937\&theSitePK=523679\&menuPK=64 187510 \&searchMenuPK $=64187511$ \&entityID $=000356161 \quad 20120214233456 \&$ cid $=3001$ 3; ; Munir Iqbal, Controlling Avian Influenza Infections: The Challenge of Backyard Poultry, 3 J Mol. Genet Med. 119 (2009). See also J. Otte et al., Evidence-Based Policy for Controlling HPAI in Poultry: Bio-Security Revisited, Research Report, Pro-Poor Livestock Policy Initiative at 2 (December 2006) available at http://www.fao.org/ag/againfo/programmes/en/pplpi/docarc/rep-hpai biosecurity.pdf (referring to the widespread assumption that backyard poultry farming is a primary source for the risk of an HPAI outbreak).
} 
significantly associated with handling diseased or dead poultry. ${ }^{27}$ In an effort to prevent and respond to HPAI outbreaks in this sector, public health experts conducted many interventions to educate village farmers about pathogens, about the risk of HPAI to their poultry and to themselves, about reporting illness among their poultry to local officials, about isolating sick poultry from the rest of the flock, about the value of vaccination, about destroying infected poultry and cleaning or destroying their coops, and about personal hygiene after coming into contact with poultry. ${ }^{28}$

\section{B. Evidence of Shifting Priorities Away From HPAI Prevention}

From 2004 through mid-2008, HPAI work was among the highest of global public health priorities. FAO reports that funding for this work increased steadily from 2004 through $2007 .^{29}$ In the peak years of 2006 and 2007, donors provided upwards of $\$ 80$ million each year for HPAI projects. ${ }^{30}$ Starting in 2008, however, funding dropped substantially. For the years 2008, 2009 and 2010, pledged funds dropped by half, averaging about $\$ 40$ million annually. ${ }^{31}$

\footnotetext{
${ }^{27}$ See Sonja J Olsen et al., Poultry-Handling Practices During Avian Influenza Outbreak, Thailand, 11 Emerging Infectious Diseases 1601 (Oct. 2005). See also CIDRAP, Avian Influenza (Bird Flu): Implications for Human Disease: H5N1 in Humans: Epidemiologic Features, available at http://www.cidrap.umn.edu/cidrap/content/influenza/avianflu/biofacts/avflu_human.html\#top.

${ }^{28}$ See e.g., id.; MH Hafez et al, Acian Influenza H5N1 Virus Infections in Vaccinated Commercial and Backyard Poultry in Egypt, 89 Poultry Science 1609 (2010); Dilip P Bhandari et al., Preventing Highly Pathogenic Avian Influenza (HPAI) at the Rural Community Level: A Case Study from Cambodia, 43 Tropical Animal Health and Production 1071 (2011); Sonja J Olsen et al., supra note 27.

${ }^{29}$ See FAO, Fourth Report (Jan - Dec 2010) of the Global Programme for the Prevention and Control of Highly Pathogenic Avian Influenza at 19 figure 2.1 (2011).

${ }^{30}$ See id.

${ }^{31}$ See id.
} 
As funding dropped, so too did the initiation of new HPAI projects. On average, 24 new projects were started each year over the seven-year period from 2004-2010. ${ }^{32}$ When annual pledges dropped, the number of annual start-up projects fell well below that average. Eighteen new projects were initiated in 2009 , and only six were started in $2010 .^{33}$ While the reductions in HPAI funding and projects coincide with the global financial crisis, ${ }^{34}$ they are more likely the result of a shift in public health priorities to address diseases at the animal-human interface other than HPAI, which shift is discussed in detail below.

At the same time, funding data also reveals a shift of priorities within HPAI work. Projects related to HPAI can be sorted into prevention work and response work. ${ }^{35}$ Prevention projects, as the name implies, are those designed to minimize the risk of infection in either poultry or humans. These specifically include projects aimed at improving the biosecurity of poultry production in developing nations. By contrast, response projects focus on the postinfection phase.

From 2005 through mid-2008, funding for HPAI work was distributed fairly evenly between prevention, on the one hand, and response programs, on the other. The UN and World Bank report that donor nations and international organizations committed about $\$ 700$ million to

\footnotetext{
${ }^{32}$ See id. at 17 figure 2.1 (based on 168 total HPAI projects through December 2010).

${ }^{33}$ See id. at 19.

${ }^{34}$ See Murray et al, Development Assistance for Health: Trends and Prospects, 378 The Lancet 9785 (July 2, 2011) (providing data showing that funding for global health programs generally declined in 2009 and 2010 shortly after the start of the global economic crisis).

${ }^{35}$ See FEMA, Fundamentals of Emergency Management, available at http://training.fema.gov/EMIWeb/edu/fem.asp (last updated August 31, 2011). Prevention work is also referred to as "risk mitigation." Response work includes, not only projects that occur after an infection, but also to pre-infection projects designed to prepare for an effective response.
} 
projects in each category from late 2005 through mid-2008. ${ }^{36}$ Starting in 2008, however, there was a dramatic change. International commitments for HPAI response programs jumped by about $\$ 1.4$ billion over about a 20-month period ending in December 2009. ${ }^{37}$ Meanwhile, only about $\$ 200$ million in new commitments were pledged for prevention projects over the same time period. ${ }^{38}$

Thus, the change in funding patterns starting in 2008 reveal a two dimensional shift in strategic priorities related to HPAI prevention. First, as global public health leaders seek to expand work other than that directly related to HPAI, projects aimed at increasing biosecurity in poultry production has become a lower funding priority. Second, within HPAI work, the priority of such prevention programs was diminished again as donors and international public health organizations shifted funding from prevention and towards HPAI response efforts. As discussed next, there are several reasons for this shift in priorities, including the H1N1 pandemic of 2009, political momentum behind the "One World, One Health" initiative and its funding needs, and revelations about the sources of HPAI risk in poultry production in developing nations as well as the difficulty of changing behaviors for the sake of improving biosecurity among backyard farmers.

\section{The Shift Away From HPAI Prevention After the 2009 H1N1 Pandemic}

The period of time over which funding for HPAI prevention projects shrunk substantially coincides with the H1N1 pandemic and the global response to it. As this section explains, the

\footnotetext{
${ }^{36}$ See UN and World Bank, Animal and Pandemic Influenza: A Framework for Sustaining Momentum at 38, figure 2-5 (July 2010).

${ }^{37}$ See id.

${ }^{38}$ See id.
} 
experience of H1N1 focused public attention on the inadequacy of the world's vaccine

production capacity. As a result, expanding that capacity and shortening the time period between isolating a novel influenza virus and having in hand the quantity of vaccine necessary to protect the world's population became top priorities.

The 2009 novel H1N1 influenza virus first emerged as a human threat in March 2009 in Mexico. ${ }^{39}$ It spread to the U.S. in April of that year, ${ }^{40}$ prompting the Acting Secretary of the U.S. Department of Health and Human Services to declare a public health emergency. ${ }^{41}$ By the end of May, the virus had moved worldwide. ${ }^{42}$ In June 2009 the World Health Organization (WHO) declared a pandemic citing several reasons. ${ }^{43}$ First, the virus was novel, ${ }^{44}$ meaning that human immunity developed from prior influenza strains offered little or no protection against the 2009 H1N1 strain. ${ }^{45}$ Second, the virus had spread rapidly infecting approximately 30,000

\footnotetext{
${ }^{39}$ CDC, Outbreak of Swine-Origin Influenza A (H1N1) Virus Infection - Mexico, March - April 2009, MMWR (April 30, 2009). For a summaryof the H1N1 pandemic, see CIDRAP, Pandemic H1N1 2009 Overview available at http://www.cidrap.umn.edu/cidrap/content/influenza/swineflu/biofacts/h1n1 panview.html (last updated December 16, 2010); CDC, The 2009 H1N1 Pandemic: Summary Highlights, April 2009-April 2010 available at http://www.cdc.gov/h1n1flu/cdcresponse.htm (last updated June 16, 2010).

${ }^{40}$ CDC, Swine Influenza A (H1N1) Infection in Two Children - Southern California, March - April 2009, MMWR (April 21, 2009); CDC, The 2009 H1N1 Pandemic: Summary Highlights, April 2009-April 2010 available at http://www.cdc.gov/h1n1flu/cdcresponse.htm (last updated June 16, 2010).

${ }^{41}$ See HHS, Determination that a Public Health Emergency Exists (April 26, 2009), available at http://www.flu.gov/professional/federal/h1n1emergency042609.html.

${ }^{42}$ WHO, Timeline of Influenza A(H1N1) Cases available at http://www.who.int/csr/disease/swineflu/interactive_map/en/index.html.

${ }^{43}$ See Statement to the press by WHO Director-General Dr Margaret Chan (June 11, 2009), available at http://who.int/mediacentre/news/statements/2009/h1n1_pandemic phase6_20090611/en/index.html.

${ }^{44}$ See id.

${ }^{45}$ See CIDRAP, Pandemic H1N1 2009 Overview available at http://www.cidrap.umn.edu/cidrap/content/influenza/swineflu/biofacts/h1n1_panview.html (last updated December $16,2010)$.
} 
individuals in 74 countries over two or three months. ${ }^{46}$ Third, it acted differently from seasonal flu, infecting young and otherwise healthy individuals in large numbers. ${ }^{47}$

In response to the pandemic, private vaccine manufacturers in cooperation with WHO and its laboratories used the isolated virus to develop a vaccine on an emergency basis ${ }^{48}$ pursuant to WHO's 2006 Global Action Plan. ${ }^{49}$ This Plan was developed following outbreaks of H5N1 bird flu in southeast Asia in 2003 and 2004 when WHO determined that global capacity for the production of pandemic vaccine was about 500 million doses per year, billions of doses short of the quantity needed to vaccinate the world's population..$^{50}$ One strategy was to finance an increase in pandemic vaccine production capacity. ${ }^{51}$ Under the Plan world production capacity by 2011 - would be sufficient to produce two billion doses of pandemic vaccine within six months of the transfer of a vaccine strain to pharmaceutical manufacturers, and - by approximately 2016 - it would be further expanded to produce 6.7 billion doses within that same time period. ${ }^{52}$

Although there had been substantial progress toward the goals set in the Plan by mid2009, the H1N1 experience made clear that the world's ability to produce and distribute a pandemic vaccine in sufficient time and supply to serve the world's population was woefully

\footnotetext{
${ }^{46}$ See Statement to the press by WHO Director-General Dr Margaret Chan (June 11, 2009), available at http://who.int/mediacentre/news/statements/2009/h1n1 pandemic phase6 20090611/en/index.html.

${ }^{47}$ See id.

${ }^{48}$ See id.

49 See WHO, Global Pandemic Influenza Action Plan to Increase Vaccine Supply (2006), available at http://www.who.int/vaccines-documents/DocsPDF06/863.pdf.

${ }^{50}$ See id. at 4.

${ }^{51}$ See id. at 7.

${ }^{52}$ See id. at 7.
} 
inadequate. The novel H1N1 influenza strain was identified and transferred to manufacturers in May 2009. ${ }^{53}$ Almost six months later in December 2009 - and more than three years into the Global Action Plan - world production of pandemic vaccine totaled 534 million doses, ${ }^{54}$ only slightly more than one-quarter of the doses called for under the Plan at the five-year mark.

As public health officials and experts assessed the lessons learned from the H1N1 pandemic, they focused on the still slow and meager production of vaccine, calling for renewed efforts to achieve the production goals established in the WHO 2006 Global Action Plan by, among other things, continuing to increase global production capacity. ${ }^{55}$ The Plan called for this increase to take place over a five-to-ten-year period. ${ }^{56}$ Thus, the global community continued to invest in building additional manufacturing capacity during and immediately after the H1N1 pandemic. Indeed, a 2010 survey revealed that seven additional vaccine manufacturing plants were under construction and are expected to come online by $2015 .^{57}$

Additionally, proposals to abandon the egg-based method of production and invest in faster methods only increased in the aftermath of the H1N1 pandemic as a way to shorten the time needed to develop an influenza vaccine. ${ }^{58}$ For example, the President's Council of Advisors

\footnotetext{
${ }^{53}$ See Partridge \& Kieny, Global Production of Seasonal and Pandemic (H1N1) Influenza Vaccines in 2009-2010 and Comparison with Previous Estimates and Global Action Plan Targets, 28 Vaccine 4709-4712 (2010).

${ }^{54}$ See id.

55 See id. See also Jadhav et al., Influenza Vaccine Production Capacity Building in Developing Countries: Example of the Serum Institute of India, 2 Procedia in Vaccinology (2010) 166-171.

${ }^{56}$ See WHO, Global Pandemic Influenza Action Plan to Increase Vaccine Supply at viii (2006), available at http://www.who.int/vaccines-documents/DocsPDF06/863.pdf.

${ }^{57}$ See Partridge \& Kieny, Global Production of Seasonal and Pandemic (H1N1) Influenza Vaccines in 2009-2010 and Comparison with Previous Estimates and Global Action Plan Targets, 28 Vaccine 4709-4712 (2010); Jadhav et al., Influenza Vaccine Production Capacity Building in Developing Countries: Example of the Serum Institute of India, 2 Procedia in Vaccinology (2010) 166-171.

${ }^{58}$ See WHO, Global Pandemic Influenza Action Plan to Increase Vaccine Supply (2006), available at http://www.who.int/vaccines-documents/DocsPDF06/863.pdf; Bryan Walsh, One Year Later: 5 Lessons from the H1N1 Pandemic, Time Magazine (April 27, 2010).
} 
on Science and Technology reviewed the problems with vaccine production during the H1N1 pandemic and concluded that valuable time could be saved by switching to existing cell-based production methods. ${ }^{59}$ So much so that the Council recommended that the U.S. invest in building new manufacturing plants capable of using the cell-based method of vaccine production. ${ }^{60}$ The Council also recommended that the U.S. invest in research to develop a genebased method of vaccine production to shave even more off of the time it takes to produce influenza vaccine during a pandemic. ${ }^{61}$ In response, HHS has provided nearly $\$ 200$ million to a private manufacturer to help finance the construction of another cell-based vaccine production facility, and it also has invested nearly $\$ 300$ million in research toward the development of genebased vaccine production methods. ${ }^{62}$

The H1N1 pandemic was a major public health moment for the world because it tested global pandemic planning and preparedness. It starkly displayed that, despite substantial efforts to expand vaccine production capacity, we lack the ability to produce pandemic vaccine quickly because of an ongoing lack of production capacity and outdated methods of production. Having witnessed the gap that still remains between our goals for vaccine production and our capabilities, it is not surprising that nations and health organizations should focus their attention and spending on closing that gap before the next influenza pandemic occurs.

One consequence, however, of a renewed focus on preparing for our response to the next pandemic is that it distracts attention and siphons funding away from efforts to prevent that

\footnotetext{
${ }^{59}$ See PCAST, Report to the President on Reengineering the Influenza Vaccine Production Enterprise to Meet the Challenges of Pandemic Influenza, part IV (Aug. 2010).

${ }^{60}$ See id.

${ }^{61}$ See id.

${ }^{62}$ See GAO, Influenza Vaccine: Federal Investments in Alternative Technologies and Challenges to Development and Licensure at 18-19 (June 2011).
} 
pandemic from occurring in first place. While it is impossible to track funding so closely as to establish conclusively that one project has been paid for at the expense of another, it is possible to identify some corroborating funding evidence. Funding for USAID avian influenza programs offers one example. This funding decreased in 2010 as compared to average spending in prior years. This is revealing because most U.S. funding for avian influenza prevention and response work in developing nations flows through USAID. ${ }^{63}$ Excluding high and low years, USAID spent on average \$146 million per year on foreign avian influenza projects from 2005 through 2009. ${ }^{64}$ In 2009, USAID spent $\$ 265$ million on foreign avian influenza projects ${ }^{65}$ - an unusually high amount most likely due to emergency spending on the H1N1 pandemic. Meanwhile, in 2010, at the same time that the White House was analyzing how to bolster the nation's pandemic vaccine production capabilities in response to the H1N1 pandemic, USAID funding for foreign avian influenza programs dropped to $\$ 125$ million. ${ }^{66}$ Moreover, this lesser funding was intended to cover not only USAID's avian influenza spending, but also its carry-over H1N1 projects. ${ }^{67}$

The UN and World Bank also noticed that a gap had developed in 2009 between international pledges toward international HPAI projects and actual funding received. It

\footnotetext{
${ }^{63}$ See USAID, USAID Advances U.S. International Engagement on Avian Flu, May 16, 2006 (press release); ISAID Launches Emerging Pandemic Threats Program, Oct. 21, 2009 (press release). See also Sophal Ear, The Political Economy of Highly Pathogenic Avian Influenza in Combodia, 10 Int'1 J of Poultry Sci. 71, (2011) (identifying USAID - and the CDC as its administrative partner - as the most active U.S. government agency in funding HPAI activities in Cambodia).

${ }^{64}$ See Congressional Research Service, Global Health: USAID Programs and Appropriations from FY2001 through FY2010 (Aug. 13, 2009).

${ }^{65}$ See id.

${ }^{66}$ See id.

${ }^{67}$ See U.S. Dept of State, Congressional Budget Justification: Foreign Operations FY2010 at 185 (2010).
} 
attributed that gap, in part, to the need of donor nations and other organizations to re-orient its influenza funding from HPAI toward H1N1 response projects. ${ }^{68}$

Given the way the H1N1 pandemic focused attention on global vaccine response capabilities, it is likely that this pandemic is partly responsible for the shift of global funding from away from HPAI prevention and toward HPAI response programs. In other words, the H1N1 pandemic revealed a weakness in the world's preparedness, and the global community responded by moving more of its scarce resources to address that weakness, including - most probably - some resources that otherwise had been used for prevention.

Yet this is not the only way that the H1N1 pandemic contributed to a reduction in HPAI prevention projects. As the next section explains, it also popularized the "One World, One Health" movement, which has now been adopted as the policy framework for combating HPAI along with many other communicable diseases sitting at the animal-human interface.

\section{Shifting Priorities and the "One World, One Health" Initiative}

The emergence of a novel H1N1 virus with pandemic potential was not just a major human public health event; it was also a big event among animal health officials and organizations, including the Food and Agriculture Organization of the UN (FAO) and the World Organization for Animal Health (OIE). ${ }^{69}$ The novel H1N1 strain infecting humans in 2009

\footnotetext{
${ }^{68}$ See UN and World Bank, Animal and Pandemic Influenza: A Framework for Sustaining Momentum at 35-37 (July 2010).

${ }^{69}$ See e.g., International Federation for Animal Health, Animal Health Industry Statement Regarding the Human Influenza A (H1N1) and Swine Influenza in Pigs, available at http://www.ifahsec.org/animal-health/zoonosesoutbreaks/influenza-h1n1/; FAO, H1N1 Communique from Dr. Joseph Domenech, Chief Veterinary Officer (May 2, 2009)(reporting flu-like illness among pigs); OIE, Pandemic H1N1 2009, available at http://www.oie.int/for-themedia/press-packs/pandemic-h1n1-2009/.
} 
originated in pigs, causing disease in those animals to which farmers and veterinarians had to respond. $^{70}$

Of key interest, however, was that the fact that the virus was a genetic reassortment of swine, avian, and human strains that was both novel and transmissible across the swine-human species barrier, among swine, and among humans. ${ }^{71}$ As a result, H1N1 confirmed the importance of veterinary public health ${ }^{72}$ in the understanding and control of zoonoses, which is defined as "[a]ny disease or infection that is naturally transmissible from vertebrate animals to humans and vice-versa"73 and includes H1N1 influenza and HPAI among many others. In fact, the $\mathrm{CDC}$ reports that "[a]bout $75 \%$ of recently emerging infectious diseases affecting humans are diseases of animal origin, and approximately $60 \%$ of all human pathogens are zoonotic.,"74

Experts in domestic animal and wildlife health have long advocated that human medicine and public health must pay close attention to diseases that exist at the interface between animals and humans. ${ }^{75}$ In the case of influenza, this interface plays a critical role in the development of potentially pandemic strains. Influenza viruses mutate rapidly and genetically resort easily. ${ }^{76}$ When different species of animals are in close proximity to each other, it creates the opportunity

\footnotetext{
${ }^{70}$ See FAO, H1N1 Communique from Dr. Joseph Domenech, Chief Veterinary Officer (May 2, 2009).

${ }^{71}$ See id.

${ }^{72}$ Veterinary public health is "[t]he contribution to the complete physical, mental, and social well-being of humans through an understanding and application of veterinary medical science." See David Waltner-Toews, Veterinary Public Health, Encyclopedia of Public Health, available at http://www.enotes.com/public-healthencyclopedia/veterinary-public-health.
}

${ }^{73}$ WHO, Zoonoses and Veterinary Public Health, available at http://www.who.int/zoonoses/en/.

${ }^{74}$ CDC, Zoonotic Diseases: When Humans and Animals Intersect, available at http://www.cdc.gov/247/CDCFastFacts/zoonotic.html.

${ }^{75}$ See Bernard Vallat, One World, One Health, available at http://www.oie.int/for-themedia/editorials/detail/article/one-world-one-health/.

${ }^{76}$ See John M. Barry, The Great Influenza: The Story of the Deadliest Pandemic in History 107-115 (2005). 
for an influenza strains unique to each of those species to resort genetically. ${ }^{77}$ This has the potential to create whole new strains that can move across species. When humans are in close contact with animals, the same phenomenon occurs and the probability increases of a novel strain that can cross between animals and humans. ${ }^{78}$ Thus, while the biological differentiation of species initially operates as a barrier against disease transmission, it also creates the opportunity for whole new strains to emerge. Of course, not every novel strain of influenza poses a threat. Even if a strain is virulent and capable of jumping from animal to human, it must also be transmissible among humans before it has pandemic potential.

Having recognized the importance of the interface among different animal species (domestic swine, domestic poultry, wild migratory birds) and humans, public health officials adopted a framework to combat HPAI even before the emergence of the 2009 novel H1N1 strain. ${ }^{79}$ It adopted the catch-phrase "One World, One Health" to capture the concept that understanding the root causes of HPAI requires that officials account for economic, social, ecological and biological factors that combine to create an environment in which a novel bird flu could arise, which, in turn, requires a unified strategy among physicians and veterinarians as well as human, domestic animal and wildlife public health workers, and ecologists. ${ }^{80}$ Such an interdisciplinary and unified strategy would permit much earlier identification of and response to HPAI threats, more efficient use of resources, and a greater chance of addressing the source of the HPAI threat rather than merely treating its symptoms. ${ }^{81}$ To achieve such a broad-based

\footnotetext{
${ }^{77}$ See id. at 112.

${ }^{78}$ See id.

${ }^{79}$ See generally FAO et al, Contributing to One World, One Health, supra note 19.

${ }^{80}$ See id. at 18-19, 51-54.

${ }^{81}$ See id.
} 
understanding of this disease environment, however, requires a major investment in building a domestic animal and wildlife public health infrastructure, including disease surveillance, reporting and data systems capable of reaching anywhere in the world as well as trained professionals to work within those systems. ${ }^{82}$ Additionally, existing animal and human health infrastructures would need to be reworked to permit joint reporting and data sharing. ${ }^{83}$ In the end, implementing the One World, One Health framework to combat HPAI requires a global investment of more than $\$ 13$ billion over at least a ten-year period of time. ${ }^{84}$

Given the enormous investment of time and money required to implement One World, One Health, it took the scare provided by the 2009 novel H1N1 virus to motivate donor nations and organizations worldwide to sign on to the plan. ${ }^{85}$ In addition to being endorsed by the major international health organizations, such as WHO, FOA, OIE, the One World, One Health approach has been adopted by the World Bank, ${ }^{86}$ the U.S. ${ }^{87}$ (now operating a "One Health

\footnotetext{
${ }^{82}$ See id.

${ }^{83}$ See id.

${ }^{84}$ See id. at 47.

${ }^{85}$ See e.g., World Bank, People, Pathogens and our Planet, Volume 1: Towards a One Health Approach for Controlling Zoonotic Diseases xii, 1 (2010) (using references to the H1N1 pandemic as a reminder of the world's vulnerability and need for a One Health approach). See also UN and World Bank, Animal and Pandemic Influenza: A Framework for Sustaining Momentum at Chapter 6 (July 2010); Andrew C. Revkin, Flu Finding Supports 'One World, One Health' View of People and Animals, New York Times blog (June 11, 2009, available at http://dotearth.blogs.nytimes.com/2009/06/11/one-world-one-health; F. Tables, One Flu for One Health, 16 Emerging Infectious Diseases, No. 4, letter to editor (April, 2010), available at http://wwwnc.cdc.gov/eid/article/16/4/09-1593_article.htm.

${ }^{86}$ See id.

${ }^{87}$ A budget line item for zoonotic disease work first appears in the Health and Human Services budget in 2008. See HHS Budget Justification FY2008 at 104-108 (2008), available at http://www.cdc.gov/fmo/topic/Budget\%20Information/appropriations budget_form_pdf/FY08 CDC CJ_Final.pdf. The 2009 HHS budget justification reports that a center for zoonotic disease was organized at CDC. See HHS Budget Justificatoin FY2009 at 101 (2009), available at http://www.cdc.gov/fmo/topic/Budget\%20Information/appropriations_budget_form_pdf/FY2010_CDC_CJ_Final.p df. The 2011 HHS budget justification reports that the center for zoonotic diseases had been integrated into the infectious disease office to create a center for emerging and zoonotic infectious diseases. See HHS Budget
} 
Office" ${ }^{88}$ as well as a Center for Emerging and Zoonotic Infectious Diseases "guided in part by a holistic 'One Health' strategy" ${ }^{\prime 89}$ ) and the European Commission. ${ }^{90}$ The One World, One Health strategy has also received significant support from public officials in China, India, the UK, and Australia. ${ }^{91}$

The One World, One Health framework, once fully implemented over the next ten years, will improve the world's ability to control HPAI through both response and prevention strategies. ${ }^{92}$ In the short-run, however, it is siphoning resources away from HPAI programs generally and from HPAI prevention projects in particular. One World, One Health potentially pulls resources away from HPAI programs generally because the initiative is not specific to HPAI. In fact, a primary goal of the initiative is to bring a wide variety disease-specific work under a larger umbrella of zoonotic disease surveillance, data-sharing, prevention and response work. ${ }^{93}$ One World, One Health will target at least 34 diseases other than any animal-based influenza, including emergent diseases such as Nipah/Hendra viruses, SARS, Monkeypox, Hanta

Justification FY2011 at 99 (2011), available at http://www.cdc.gov/fmo/topic/Budget\%20Information/appropriations budget form pdf/FY2011 CDC CJ Final.p df.

${ }^{88}$ See http://www.cdc.gov/onehealth/. The CDC also operates a global disease detection program that, among other things, helps build global disease detection capacity in part by improving training in zoonotic diseases. See http://www.cdc.gov/globalhealth/gdder/gdd/.

${ }^{89} \mathrm{CDC}$, About the National Center for Emerging and Zoonotic Infectious Diseases, available at http://www.cdc.gov/ncezid/index.html.

${ }^{90}$ See ECDC “One Europe, One Health” press release (February 13, 2009).

${ }^{91}$ See Barry Bousfield \& Richard Brown, One World One Health, Veterinary Bulletin, Vol., No. 7 at 4 (Sept 2011), available at http://www.afcd.gov.hk/english/quarantine/qua_vb/files/OWOH2.pdf.

${ }^{92}$ See FAO et al, Contributing to One World, One Health: A Strategic Framework for Reducing Risks of Infectious Diseases at the Animal-Human-Ecosystems Interface (October 2008), available at http://uninfluenza.org/node/2341/.

${ }^{93}$ See UN and World Bank, Animal and Pandemic Influenza: A Framework for Sustaining Momentum at Chapter 5 (July 2010). 
viruses, Rabies, Rift Valley Fever, and Q Fever as well as food borne diseases like brucellosis and anthrax. ${ }^{94}$ While it is certainly possible for international health organizations and donor nations to fund and operate programs on a wide variety of diseases at once without diminishing the resources available for HPAI work, it is equally possible that HPAI projects are neglected as resources are stretched over a larger number of disease priorities based on the One World, One Health initiative. ${ }^{95}$

In addition to drawing attention and resource to zoonotic diseases other than HPAI, the One World, One Health initiative is also likely to shift funding within HPAI work from prevention and toward response projects. To become operational One World, One Health requires a coordinated animal-human health infrastructure that does not currently exist and will take at least ten years to build at an initial cost of at least $\$ 13$ billion. ${ }^{96}$ This is a substantial financial burden on the public health budgets of donor nations and international health organizations that threatens to consume resources that might otherwise be spent on HPAI projects. In fact, $\mathrm{FAO}$ - the international agency responsible for implementation of the One World, One Health frame work - has acknowledged that this siphoning effect is occurring. It noted the following when explaining why funding for new HPAI projects plummeted by 94 percent in the two-year period from 2008 to 2010 :

This trend is at least in part due to the broader contextual changes taking place in the thinking within the international animal health and donor community on the need to

\footnotetext{
${ }^{94}$ See id. at 83 , figure $5-2$.

${ }^{95}$ For the phenomenon that funding one public health priority can displace funding for another, see Grace Lordan et al., Has HIV/AIDS Displaced Other Health Funding Priorities? Evidence from a New Dataset of Development Aid for Health," Queensland University School of Economics Discussion Paper No. 422, available at http://pandora.nla.gov.au/pan/53288/20110328-1427/422.pdf (Feb. 2010); Jeremy Shiffman et al, Has Aid for AIDS Raised all Health Funding Boats? 52 Journal of Acquired Immune Deficiency Syndromes S45 (Nov. 2009).

${ }^{96}$ See UN and World Bank, Animal and Pandemic Influenza, supra note 5, at 115 (estimating an annual cost of \$1.3 billion over 10 years).
} 
move away from disease specific interventions to a more holistic and integrated approach to building sustainable animal health systems at country, regional and global levels. ${ }^{97}$

The statement about "moving away from disease specific interventions" and toward "a more holistic and integrated approach" is a direct reference to the One World, One Health concept.

Moreover, any shift of resources has and will continue to disproportionately affect HPAI prevention projects as compared to response programming. This is because so much of the One World, One Health infrastructure is a designed to respond to zoonotic disease outbreaks, including HPAI. The initiative seeks the capability to survey a wide variety of diseases in their domestic animal, wild animal, and human hosts anywhere in the world so that an outbreak response can begin quickly at the very source of the problem. Thus, all of the surveillance systems, interdisciplinary coordination, data-sharing, and animal health training that the initiative seeks to build over the next ten years have the primary purpose of preparing for and responding to a disease outbreak. ${ }^{98}$ Prevention is certainly part of the initiative, and information gathered using the response infrastructure envisioned by One World, One Health is valuable to a prevention effort. Yet, they are not investments directly in prevention. While building the response infrastructure first may certainly be a prudent strategy, it is crowding-out HPAI prevention and assigning it a lower priority at least until the One World, One Health infrastructure has been completed.

The shift of resources toward the project of building the One World, One Health infrastructure and is already evident in now dormant HPAI programming that was once funded through international aid departments of the US and UK governments. For example, a project

\footnotetext{
${ }^{97}$ See FAO, Fourth Report (Jan - Dec 2010) of the Global Programme for the Prevention and Control of Highly Pathogenic Avian Influenza at 19 (2011).

${ }^{98}$ See Ian Scoones \& Paul Forster, One World, One Health?, RuRAl21: The InT’L J. OF RuRAL Dev. 22 (June 2009) (criticizing One World, One Health initiative as outbreak centric) available at http://www.rural21.com/uploads/media/R21_One_World_One_Health_0609.pdf.
} 
aimed at preventing HPAI infections through improved biosecurity education among small-scale farmers in developing nations closed as of January $2011 .^{99}$ It was operated by the International Food Policy Research Institute and was funded primarily by the UK's Department for International Development. ${ }^{100}$ No other UK-funded project seems to be taking its place. Likewise, a USAID-funded project called "STOP AI" was funded only through mid-2010. ${ }^{101}$ Additionally, a similar USAID-funded project in Indonesia has ended, ${ }^{102}$ and no other USAID funding appears to be going directly to any other HPAI projects. In fact, all of the USAID HPAI projects are closely related to the goal of building the One World, One Health infrastructure. In its 2011 summary of its health programs, USAID notes that it will continue to fund a grant to FAO as the lead international organization in combating zoonotic disease as well as an international program to develop a global warning system for emerging wildlife diseases. ${ }^{103}$ In the end, the One World, One Health initiative, and, in particular, its effort to build a new zoonotic disease response infrastructure over the next ten years, is one of the major reasons for the diminishment of funding for HPAI projects generally and for HPAI prevention projects specifically. The siphoning of resources away from HPAI is likely to continue for at least as long as it takes to complete the One World, One Health infrastructure.

\footnotetext{
${ }^{99}$ See DFID, Project details, Pro-Poor Options for Control of Highly Pathogenic Avian Influenza in Africa and South East Asia, available at http://projects.dfid.gov.uk/project.aspx?Project=112199. 


\section{E. Shifting Priorities and the Complexity of HPAI Prevention}

A third reason why global funding for HPAI work has shifted dramatically away from prevention projects is that they are highly complex projects designed to change the behaviors of poultry producers, and they have had very limited effect to date. To succeed, these projects require a great deal of time and - thus - funding, and they must be narrowly targeted. In the long-run, they are likely worth the investment because prevention work makes it more likely that we avoid the start of an expensive pandemic. In the short-run, however, they are a much less attractive investment of resources precisely because they will continue to have only limited effect. All of this is explained in greater detail in this section.

HPAI prevention projects focus on preventing the infection of poultry in the first place, or, if poultry are infected, then preventing the transmission of that infection to any human, or both. The common tools for preventing infection of a flock, especially when poultry are kept in densely populated commercial production facilities, include: routine disinfection of poultry living spaces as well as processing equipment; isolation of new additions to a flock until it is determined that they are disease-free; isolation of any diseased bird from the healthy flock; either spot or mass vaccination of healthy poultry; culling and proper disposal of diseased birds. ${ }^{104}$

It can be extremely difficult to implement these tools in the various poultry farming sectors in many developing nations. For one, there may not be an economic incentive for the poultry producer to assure that the producer's poultry is disease free. ${ }^{105}$ If consumers in the particular location are not demanding verification that poultry are disease free, then neither those

\footnotetext{
${ }^{104}$ See Jessica H. Leibler et al., supra note 15; FAO et al., Pro-Poor HPAI Risk Reduction: Lessons from Southeast Asia and Africa at 13 (Oct. 2010) (research meeting proceedings), available at http://www.dfid.gov.uk/r4d/PDF/Outputs/HPAI/WKS101025_puket_proceedings.pdf.

${ }^{105}$ See id.
} 
who operate the markets in which poultry are sold nor those who produce the poultry are likely to consider the risk unless there is an outbreak that shuts down business for a time. Moreover, taking steps to create a production environment or a market environment where disease is unlikely to occur imposes additional costs that a producer or market operator will not incur unless there is a market demand for undertaking those costs. ${ }^{106}$ Thus, prevention projects often must use small pilot projects to estimate whether consumers would pay a higher price for chicken that has been produced and marketed in such a way as to assure that it is disease free, and, if so, how much more they would likely pay. ${ }^{107}$ This is then used to persuade producers and marketers that it is worth undertaking the additional costs.

Even still there will be difficulty because different size poultry producers will be able to absorb those costs differently. While undertaking costs associated with isolating birds, disinfecting birds, vaccinating birds, etc. may be feasible for large commercial producers, the same is not necessarily true for smaller commercial producers and backyard farmers. For some the size of their flock is too small to justify the initial investment even if there is a market for chicken that is guaranteed to be disease free. ${ }^{108}$ Thus, many producers must decide whether to increase the size of their operations or to operate as part of "black market" or to stop producing poultry all together. ${ }^{109}$ Where prevention depends on those sorts of major changes in the structure of the market, prevention will come slowly if at all.

\footnotetext{
${ }^{106}$ See J. Ifft et al., Poultry Certification for Pro-Poor HPAI Risk Reduction 1-2 (Working Paper) (2009) available at http://www.dfid.gov.uk/r4d/Output/179169/Default.aspx.

${ }^{107}$ See e.g., id.; D. Roland-Holst et al., Pilot Programme for Certified Smallholder Poultry Supply Chains for Hanoi (research report) (Nov. 6, 2006) available at http://www.fao.org/ag/againfo/programmes/en/pplpi/docarc/rephpai traceability.pdf.

${ }^{108}$ See Anni McLeod, supra note 23.

${ }^{109}$ See FAO, The Global Strategy for Prevention and Control of H5N1 Highly Pathogenic Avian Influenza 9 (March 2007) available at http://www.fao.org/docs/eims/upload/210745/glob_strat_HPAI_apr07_en.pdf.
} 
A second reason it can be difficult to change behaviors among commercial poultry producers and marketers is that they may distrust government and outside influence, which can make it nearly impossible to learn what the producers' behaviors are in the first place and to verify that new behaviors are occurring. ${ }^{110}$ Several developing nations lack a strong regulatory environment in which officials are authorized to inspect private businesses. ${ }^{111}$ Thus, officials and prevention project workers are left to appeal to the good will of the producer or marketer to allow an inspection and to discuss changing behaviors. Where distrust exists of the government or of outsiders or both, this distrust can be a substantial barrier to implementing any prevention measures. Thus, project workers often find themselves first building trust among the community before engaging in any attempt to change behavior. Additionally, trust is generally built slowly on a person-to-person basis, which means that the initial phase of the project can take a very long time indeed.

A third and related reason prevention work is difficult is that governments in some developing nations are quick to cull diseased poultry - often more than is necessary to stop the disease - but very slow to provide compensation for culled poultry. ${ }^{112}$ Again, this affects different poultry producers differently depending on their size. Large producers generally have

\footnotetext{
${ }^{110}$ See FAO, One Health: Seeing Around Corners: A Regional Communication Strategy Framework Against Infectious Diseases in Asia and the Pacific 2011-2016 12, 28 (Aug. 2011) available at http://www.fao.org/docrep/015/an167e/an167e00.pdf; Ian Scoones \& Paul Forster, The International Response to Highly Pathogenic Avian Influenza: Science, Policy and Politics, Steps Centre Report 18, 48 (2008) available at http://www.steps-centre.org/PDFs/Avian\%20flu\%20final\%20w\%20cover.pdf.
}

${ }^{111}$ See OIE, Recommendations of the OIE Global Conference on Veterinary Legislation, Recommendation no. 7 (Dec. 2010); OIE, Guidelines on Veterinary Legislation sections 2.8-2.11 available at http://www.oie.int/support-tooie-members/veterinary-legislation/. See also FAO, Fourth Report (Jan-Dec. 2010) of the Global Programme for the Prevention and Control of Highly Pathogenic Avian Influenza at 80-146 (2011) (repeatedly finding that a lack of adequate regulation contributes to HPAI's being endemic in many southeast Asian countries).

\footnotetext{
${ }^{112}$ See Sayako Kanamori \& Masamine Jimba, Compensation for Avian Influenza Cleanup, 13 Emerging Infectious
} Diseases 341 (2007). 
the financial means to absorb losses brought on by culling while smaller producers often do not. As a result, the smallest producers have an incentive to hide their poultry from officials ${ }^{113}$ and sell them quickly on a black market or to consume them personally. ${ }^{114}$ Thus prevention projects often must first help establish a culling compensation program that operates for some time so as to establish trust in the community that it is safe to report disease and to cooperate with a program of culling. ${ }^{115}$

Prevention projects have had the most success among large commercial producers because they have been able to persuade producers that selling poultry guaranteed to be disease free is profitable in both the short and long runs. ${ }^{116}$ Yet, success has come slowly for the reasons explained above. Because of these successes, prevention work has focused on developing public-private partnerships designed to create standards for hygienic and biosecure poultry production as well as systems for helping consumers to verify that the chicken they are buying was produced in such an environment. ${ }^{117}$ In fact, the One World, One Health initiative has adopted this public-private approach for its prevention work. ${ }^{118}$

While harnessing market incentives and creating biosecurity standards may work for large commercial producers, this will not work with many small-scale producers and backyard

\footnotetext{
${ }^{113}$ See R.G. Alders \& R.A.E. Pym, Village Poultry: Still Important to Millions, Eight Thousand Years After Domestication, 65 World's Poultry Science Journal 181, 187 (June 2009); McLeod, supra note 108 at 376.

${ }^{114}$ See e.g. John M. Omiti \& Sam O. Okuthe, supra note 20 at 66.

115 See R.G. Alders \& R.A.E. Pym, Village Poultry: Still Important to Millions, Eight Thousand Years After Domestication, 65 World's Poultry Science Journal 181, 187 (June 2009); McLeod, supra note 108 at 376.

${ }^{116}$ See J. Otte et al, DFID-Funded Collaborative HPAI Research Project for Asia and Africa, powerpoint presented at the International Meeting on Pro-Poor HPAI Risk Reduction, message \#10 (Oct. 25 2010), available at http://www.hpai-research.net/docs/PRE101025_Otte_results_summary.pdf.

117 See McLeod, supra note 108 at 375-376. See also FAO, supra note 19 at 32-33.

${ }^{118}$ See UN and World Bank, supra note 5 at 60.
} 
farmers. Small-scale commercial producers, as explained above will likely find that it is too costly to abide by those standards given the size of his flock, in which case the producer must decide whether to grow, get out of the business, or ignore the standards. ${ }^{119}$

Backyard farmers are altogether different, and changing their husbandry practices is even more time consuming and difficult than changing the behaviors of commercial producers. One reason for this is that they tend to be very poor. ${ }^{120}$ With few resources, there is nothing to spend on cages or cleaning equipment or fencing. As a result, chickens roam out in the open on village roads, in residential yards and in residences themselves. ${ }^{121}$ This creates more of an opportunity for influenza to spread from bird to bird and from bird to human. Additionally, village chickens are much more likely than commercial birds to come into contact with other domesticated animals such as pigs or wild birds that also live in the area or are migrating. ${ }^{122}$ This creates a chance for an influenza virus to move from animal species to animal species, increasing the odds of a dangerous genetic re-assortment and a novel virus.

The fact that most backyard poultry farmers are extremely poor also means that they are more dependent on their chickens as a source of food or income or both. ${ }^{123}$ Consequently, they are very unlikely to cooperate with any disease surveillance program that might result in their

\footnotetext{
${ }^{119}$ See McLeod, supra note 108 at 376.

${ }^{120}$ See Juan Lubroth et al, Global Strategy for Highly Pathogenic Influenza: Progressive Control and Eradication, and Postoutbreak Recovery in AviAn InFLuENZA 566 (David E. Swayne, ed.) (2008); UN \& World Bank, supranote 5 at 24 (case study 1-4).

${ }^{121}$ See Yemane Berhane \& Admas Tefera, Avian Flu Pandemic Threat: Why Is Ethiopia Considered At Risk, 19(3) Ethiopian Journal of Health Development 165-166 (2005).

${ }^{122}$ See supra notes 21 through 25 and the accompanying text.

${ }^{123}$ See FAO, The View From the Farm: Communication Challenges in the Time of EIDs (power point presentation), available at http://www.hpai-research.net/docs/PRE101025_Gopinath.pdf. See also R.G. Alders \& R.A.E. Pym, Village Poultry: Still Important to Millions, Eight Thousand Years After Domestication, 65 World's Poultry Science Journal 181, 182, 183-184 (June 2009).
} 
losing some or all of their flocks. ${ }^{124}$ Instead, they are far more likely to create other opportunities for transmission of influenza by eating an infected chicken or selling or trading it outside of the village. ${ }^{125}$ As a result, a successful prevention program must employ "pro-poor strategies" for increasing biosecurity without much if any financial outlay for the farmer. So, for example, a backyard farmer is unlikely to have the resources to purchase disinfectant on a regular basis. Consequently, a public health worker might, as an alternative, recommend that a farmer burn and rebuild a coop in which infected chickens resided.

Another characteristic of backyard poultry farms in many developing nations is that they are located in villages that tend to be in remote locations. As a result, they are unlikely to be part of commercial networks of any real significance. ${ }^{126}$ Consequently, market incentives are very unlikely to motivate the backyard poultry farmer to make his farm more biosecure.

A third characteristic of backyard poultry farmers in developing nations is that they tend to have a limited understanding of pathogens and disease transmission. ${ }^{127}$ In fact, their understanding of disease can often be based on myths that lack scientific foundation. ${ }^{128}$ Thus, in many instances, public health workers first must become familiar with the level of understanding

\footnotetext{
${ }^{124}$ See McLeod, supra note 108 at 376.
}

125 See supra note 114.

${ }^{126}$ See R.G. Alders et al., Small-Scale Family Poultry Production, 66 World's Poultry Science Journal 434, 436 (Sept 2010) (listing "lack of market access" as a major feature of backyard poultry farmers in villages in Asia, Africa, and Latin America).

127 See id. at 435. See also FAO, The View From the Farm: Communication Challenges in the Time of EIDs (power point presentation), available at http://www.hpai-research.net/docs/PRE101025_Gopinath.pdf.

${ }^{128}$ See FAO, The View From the Farm: Communication Challenges in the Time of EIDs (power point presentation), available at http://www.hpai-research.net/docs/PRE101025_Gopinath.pdf. 
about disease so as to design a method to challenge any myths in order to teach basic lessons about pathogens and their transmission. ${ }^{129}$

Finally, language can also be a challenge for public health workers running a HPAI prevention project in a village with backyard poultry farmers. ${ }^{130}$ Remote villages in some developing nations might speak a different dialect of the prominent national language or secondary, indigenous language. Program workers must always be careful to learn the precise meaning of the words they intend to use in communicating public health messages to farmers and villagers. ${ }^{131}$ This is to avoid using a word that has one meaning in the nation's capital and a different meaning in that village. ${ }^{132}$

Because of these common characteristics of backyard poultry farmers in developing nations where HPAI is endemic, public health workers must take a great deal of time to design and implement an intervention that is tailored to the particular characteristics of that village. ${ }^{133}$ Consequently, the work is very slow - even slower than prevention projects in the commercial sectors - and presents an even greater chance of failure. Moreover, because of the idiosyncrasies of each village, lessons learned in one village may not be applicable to the next village. Consequently, it can take a large number of workers and a lot of time for prevention programs to make a real difference among backyard poultry farmers.

\footnotetext{
${ }^{129}$ See R.G. Alders \& B. Bangol, Effective Communication: The Key to Efficient HPAI Prevention and Control, 63 World's Poultry Science Journal 139, 140 (2006).

${ }^{130}$ See id. at 141. See also FAO, The View From the Farm: Communication Challenges in the Time of EIDs (power point presentation), available at http://www.hpai-research.net/docs/PRE101025_Gopinath.pdf.

${ }^{131}$ See FAO, The View From the Farm: Communication Challenges in the Time of EIDs (power point presentation), available at http://www.hpai-research.net/docs/PRE101025 Gopinath.pdf.

132 See R.G. Alders \& B. Bangol, supra note 129 at 143.

${ }^{133}$ See R.G. Alders \& B. Bangol, supra note 129 at 142-143. See also McLeod, supra note 108 at 376.
} 
Given these complexities, it is understandable why officials and donor countries might question the strategy of investing equally in prevention and response programs. If those programs cannot produce measureable improvements in biosecurity in the short run, then it is reasonable to plan for the probability that the next novel influenza with pandemic potential cannot be prevented. It follows then that policy makers might shift funding from prevention programs to response programs at least in the short run with the intent to shift funding back to prevention programs only when sufficient global response systems are in place. ${ }^{134}$

Whether this was the thinking behind the shift of funding from prevention programs to response projects that the UN and World Bank observed in 2008 through 2010 is impossible to establish conclusively. Yet there is anecdotal evidence that donor nations and international health organizations were learning about the complexities of prevention programs generally (and prevention programs aimed at backyard farming in particular) during the same time period as the shift in funding was taking place.

Consider, for example, a July 2009 report by an independent auditor of a USAID-funded prevention and response project in Indonesia. ${ }^{135}$ The report reveals that, at a mid-point of the project, funders discovered that the work with backyard farmers was having very limited success and that the primary incidence of HPAI among poultry was in the commercial sectors. ${ }^{136}$ The

\footnotetext{
${ }^{134}$ See J. Otte et al, DFID-Funded Collaborative HPAI Research Project for Asia and Africa, powerpoint presented at the International Meeting on Pro-Poor HPAI Risk Reduction, message \#8 (Oct. 25 2010), available at http://www.hpai-research.net/docs/PRE101025 Otte results summary.pdf. The key slide reads:
}

Attempting to improve the bio-security of millions of backyard producers is an ineffective use of scarce resources in the GMS countries, especially public funds in countries with many high priority development objectives. Interventions targeting market-oriented producers and management of the main poultry flows from production to consumption centres is likely to be more cost-effective.

${ }^{135}$ See Brian Perry et al, Independent Evaluation of FAO's Participatory Disease Surveillance and Response Programme in Indonesia 44 (July 2009) (final report for FAO Evaluation Service) available at http://www.fao.org/docs/eims/upload/262940/PDSR\%20evaluation \%20report $\% 2030 \% 20 J u l y \% 20$ final.pdf.

${ }^{136}$ See id. at 25-29. 
auditors discovered that public health workers, despite having substantial funding and despite running many well-organized training sessions among backyard farmers, could not identify that these training sessions changed farmers' behaviors. ${ }^{137}$ This explained why funding of the project changed dramatically when funds for training and prevention in the backyard sector was shifted to commercial sectors. ${ }^{138}$ This, of course, coincides with the timing of the global shift of funding observed by the UN and World Bank that took place starting in mid-2008. ${ }^{139}$

Thus, this 2009 audit provides a good example of the logic behind moving prevention funding from backyard farmers to commercial poultry producers. Commercial producers were growing rapidly and were managing larger flocks, and, in this way, presented an opportunity for greater incidence of HPAI. Additionally, commercial producers were tied into marketing networks, which provided an opportunity HPAI to be spread among participants in the markets when flocks were sold among suppliers or slaughtered and sold at the retail level. Meanwhile backyard farmers had smaller flocks and were only sporadically and remotely tied to market networks. This explained why the incidence of HPAI among backyard farmers was lower than among commercial producers. Yet, backyard farmers were susceptible to infection once HPAI emerged among their birds because of their close physical connection to their poultry and their limited understanding of or ability to implement more biosecure husbandry. As the independent

\footnotetext{
${ }^{137}$ See id. at 55-59.

${ }^{138}$ See id. at 25-29.

${ }^{139}$ See UN and World Bank, Animal and Pandemic Influenza: A Framework for Sustaining Momentum at 3?-3? (July 2010).
} 
auditor put it, "sector 4 [the backyard farming sector] probably represents the sentinel victim of infection, rather than the 'engine room' of HPAI dynamics."

\section{Conclusion: Shifting Priorities and HPAI Control Over the Next Ten Years}

This Article identified three possible reasons that combine together to explain why the global public health community, in 2008, dramatically shifted funding from prevention programs aimed largely at poor backyard poultry farmers and toward response projects as well as prevention and response projects aimed at large commercial poultry producers. In so doing, it reveals a shift in public health priorities that has taken place.

First and foremost, while officials, international health organizations, and donor countries have not given up on preventing the next influenza pandemic, they have become much more focused on preparing the world to respond to an HPAI outbreak. Additionally, they have determined that our ability to respond depends on incorporating animal health information into our understanding of the public health risks of pandemic influenza. This is reflected in the work of FAO, OIE, WHO and the World Bank planned over the next ten years to implement the One World, One Health framework. Moreover, some individual countries along with some international health organizations emphasize that global preparedness for the next influenza pandemic turns on our ability to improve the speed with which we manufacture a vaccine.

Based on these priorities, we will witness a substantial increase in animal health infrastructure as well as a coordination of data-sharing systems between animal and human

\footnotetext{
${ }^{140}$ Brian Perry et al, Independent Evaluation of FAO's Participatory Disease Surveillance and Response Programme in Indonesia 44 (July 2009) (final report for FAO Evaluation Service) available at http://www.fao.org/docs/eims/upload/262940/PDSR\%20evaluation\%20report\%2030\%20July\%20final.pdf.
} 
health officials. Additionally, we will see a deliberate effort at interdisciplinary cooperation with respect to public health work on all zoonotic diseases.

A second priority revealed by this analysis is that time is of the essence and so investments in HPAI programs must pay dividends in the short run. This is revealed both in the emphasis that has been placed on funding the creation of new surveillance and data-sharing systems as part of the One World, One Health initiative and the decision to prevent infections by focusing on large commercial poultry production sites and using market incentives to generate quick improvements in biosecurity all across that sector of the poultry market.

As indicated throughout this Article, we should expect as a result of this focus on shortrun gains that HPAI prevention projects will be fewer over the next ten years, and what projects are funded will likely exclude backyard farmers where market incentives are a much less effective tool for promoting biosecurity. This creates a great risk that the interests of backyard farmers, their families and their villages will not be adequately protected while short-run projects are a high priority. Specifically, the risk is that we will see a spike in HPAI infections humans among villagers where backyard farming takes place because so few resources are likely to be spent on educating those individuals about how to protect their poultry and themselves. Additionally, there is the risk that HPAI infections among animals will spike as well, which also threatens the welfare of backyard farmers by significantly diminishing or wiping out poultry flocks that are a source of both income and food.

Of course, the short-run strategy also is risky for what it ignores in the long-run. It is like the old saying - an ounce of prevention is worth a pound of cure. Investment in HPAI prevention is, in the long-run, a necessary investment because preventing a pandemic is so much less expensive than fighting it after it has emerged. Consequently, using international resources 
to build the "One World One Health" infrastructure and to target HPAI prevention among commercial producers in developing countries may be valuable and even efficient, but it should not happen at the expense of prevention projects aimed at protecting backyard poultry farmers, who are among the most vulnerable potential victims of bird flu. 